\title{
GRISELDA GAMBARO Y EL TEATRO DE LA CRUELDAD ARTAUDIANO: UN LUGAR CRÍTICO REVISITADO
}

\author{
Ana Sánchez Acevedo \\ Universidad de Sevilla
}

\begin{abstract}
Resumen: El presente trabajo pasa revista a las referencias críticas más destacadas que, desde los años 70, vienen aludiendo a las posibles relaciones de similitud, influencia o parentesco entre el teatro de la crueldad artaudiano y las concepciones dramáticas de Griselda Gambaro en su producción teatral de neovanguardia. Partiendo de ese estado de la cuestión y de la relectura y contextualización de las ideas recogidas por Artaud en El teatro y su doble, se analizan y discuten los alcances específicos de este lugar crítico.
\end{abstract}

Palabras clave: Griselda Gambaro, Antonin Artaud, teatro de la crueldad, teatro latinoamericano, teatro del absurdo.

Abstract: This paper reviews the most significant critical references that, since the 70's, are referring to the possible influences or relations of resemblance between Artaud's Theater of Cruelty and Griselda Gambaro's dramatic ideas in her neo-avantgarde theater. Starting from this review and from the re-reading and contextualization of the ideas collected by Artaud in The Theatre and Its Double, the specific scope of this critical issue is analyzed and discussed.

Keywords: Griselda Gambaro, Antonin Artaud, Theatre of Cruelty, Latin American Theatre, Theatre of the Absurd.

\section{Artaud en el teatro latinoamericano: panorama general}

El estudio de la difusión, la recepción y las distintas influencias de los planteamientos teatrales de Artaud en el vasto campo de la producción dramática latinoamericana es una tarea crítica que en su mayor parte está todavía pendiente, y muy especialmente en lo que se refiere a la elaboración de panorámicas de conjunto que permitan ubicar, sopesar y explicar de un modo riguroso, profundo y abarcador los análisis fundamentalmente específicos y parciales, centrados en unas pocas obras o autores concretos, de los que se ha partido por lo general hasta el momento. En un artículo publicado en 1990, hoy de referencia obligada para esta cuestión, Karl Alfred Blüher hacía notar esta falta de "una investigación completa sobre la recepción de Artaud en el teatro latinoamericano” 
(113) que permitiera superar el carácter "todavía extremadamente fragmentario e inexacto" de nuestro conocimiento al respecto (114), situación de carencia que, más de diez años después, parece seguir siendo muy semejante en lo esencial.

Aunque circunscribiendo su aportación — como ha sido frecuente, y he ahí uno de los problemas que iremos considerando- al ámbito de la recepción de Artaud en los autores y en su concepción de las obras teatrales, Blüher señalaba además la pertinencia de distinguir otras dos esferas posibles de recepción de las ideas artaudianas: en los directores y sus puestas en escena, y en la formación de actores (Blüher, 113). Ahora bien, tal como el propio crítico advierte, nos encontramos ya aquí con un posible escollo, pues una diferenciación de ese tipo entra aparentemente en contradicción directa con la concepciones artaudianas recogidas en El teatro y su doble acerca de un creador único en el que se disuelva la dicotomía autor-director ${ }^{1}$, y que incluyen también todo un proyecto de formación y redefinición del actor como parte del conjunto orgánico de su teatro de la crueldad $^{2}$.

Esto nos lleva a la necesidad de establecer una aclaración de índole general como punto de partida, tanto para nuestro análisis posterior enfocado en el caso concreto de la argentina Griselda Gambaro, como para cualquier investigación más amplia sobre las posibles influencias artaudianas en el teatro latinoamericano. Según deja también apuntado Blüher en su trabajo (113), la recepción de Antonin Artaud, no sólo en Hispanoamérica sino a nivel internacional, no ha tomado nunca los postulados del teatro de la crueldad como un conjunto organizado e interdependiente a modo de concepto total, sino que se ha tendido a entresacar y asimilar únicamente componentes particulares y parciales del grueso de sus teorías. De ahí que resulte imprescindible para el estudio de esta recepción desprenderse en cierta medida de una consideración estricta,

1 Siguiendo las palabras de Artaud, la puesta en escena tendrá que ser "el punto de partida de toda creación teatral. Y en el empleo y en el manejo de ese lenguaje se disolverá la antigua dualidad de autor y director, reemplazados por una suerte de creador único, al que incumbirá la doble responsabilidad del espectáculo y la acción” (106). “El autor habrá de descubrir y asumir lo que pertenece a la puesta en escena, tanto como lo que pertenece al autor, pero transformándose a la vez en director, de manera que cese esta absurda dualidad actual de director y autor" (127). "A mi entender, sólo tiene derecho a llamarse autor, es decir creador, quien tiene a su cargo el manejo directo de la escena" (133). Este es precisamente uno de los puntos conflictivos que consideraremos para el estudio ya específico de las posibles influencias concretas de los postulados de Artaud en el teatro de Griselda Gambaro, limitadas entre otras cosas en la medida en que precisamente se trata de una dramaturga, escritora y no directora, y por tanto en teoría, si siguiéramos literal y rigurosamente a Artaud, sin derecho de llamarse propiamente autora, creadora.

2 Como ha señalado Jorge Dubatti, la importancia de la formación y redefinición actoral en el teatro de la crueldad artaudiano, tal como quedó formulado en El teatro y su doble, no puede minimizarse ni restringirse únicamente al capítulo específicamente dirigido al actor bajo el título "Un atletismo afectivo", pues "en realidad cada línea de El teatro y su doble involucra al actor, porque Artaud está definiendo un tipo de teatro cuyas pautas redefinen las técnicas, la función y la poética del actor" (Dubatti, 73). De nuevo se trata de un aspecto restringido a posibles influencias en el caso de Griselda Gambaro, escritora. 
severa e íntegramente literal de cada una de las ideas ataudianas, pese al carácter interrelacional y radical que, a nuestro juicio, sostiene precisamente buena parte del entramado de esas ideas.

No obstante, y en inmediata relación con lo anterior, otro problema añadido se deriva de la propia naturaleza no metodológica ni sistemática de los textos sobre teatro de Artaud y de la falta, asimismo, de un modelo real de escenificación que hubiera plasmado en última instancia las aspiraciones de su teatro de la crueldad. Como señala el crítico argentino Jorge Dubatti, "la no codificación cerrada de esta poética explícita está cerca del programa de investigación/ experimentación y lejos de la preceptiva", pues "esta última requiere una extensa práctica anterior y codificación cerrada referida al alto grado de previsibilidad genérica de esa práctica" (71). Una carencia de codificación a la que se une la ausencia de esa realización concreta que pudiéramos identificar como puesta en escena modelo, ya que "el malogrado espectáculo Los Cenci (1935) fue sólo un intento fallido, y no ha de tomárselo como la realización escénica del Teatro de la Crueldad (tal vez sí como la constatación de su imposibilidad, de acuerdo con Jacques Derrida)", y "el anunciado en el 'Segundo Manifiesto' como 'primer espectáculo del Teatro de la Crueldad', La conquista de México, nunca se estrenó" (Dubatti, 71).

En todo caso, la diversidad de lecturas, usos, adaptaciones y variaciones interpretativas en torno a las teorías dramáticas de Artaud a lo largo del siglo XX es un hecho que verifica su versatilidad. "La poética explícita de El teatro y su doble", comenta Dubatti a este respecto, "es lo suficientemente abierta como para propiciar interpretaciones y apropiaciones diferentes. La historia de la recepción teórica y práctica de este libro - que no ha dejado indiferente a ninguno de los grandes teatristas del siglo XX: Peter Brook, Jerzy Grotowski, el Living Theatre, Tadeusz Kantor, John Cage, Ariane Mnouchkine, Fernando Arrabal, etc.constituye un capítulo fascinante de la historia del teatro universal y es a la vez la demostración de que las palabras de Artaud (en especial el término 'crueldad', tan opaco y sugestivo) pueden ser comprendidas de maneras diversas" (72). Y he aquí otro punto que contribuye a hacer más complejo el análisis, y particularmente en lo que toca a Latinoamérica, pues junto a la tardía difusión y recepción directa de El teatro y su doble, y mezclada con ella, ha sido con frecuencia de forma indirecta como se han asimilado y extendido en el teatro hispanoamericano distintas versiones reformuladas de ciertos principios de raigambre artaudiana, a través de métodos como el del Living Theatre, los de Jerzy Grotowski o Eugenio Barba (Blüher, 114), el happening, o el llamado "teatro del absurdo" europeo, entre otros.

Hay que tener en cuenta además que las propuestas de Artaud no constituyen, ni mucho menos, un hecho aislado o sin precedentes en su contexto de aparición, pues forman parte de todo un movimiento más amplio de rebelión contra el teatro naturalista y el drama burgués que va a marcar la renovación de 
la escena moderna en Europa desde muy al principio del siglo XX ${ }^{3}$. Un conglomerado de impulsos renovadores que, aunque de nuevo tardíamente, también tendrá sus ecos — directos e indirectos; parciales y/o de conjunto- en el panorama hispanoamericano.

Recordemos, por ejemplo, que ya en 1905 Gordon Craig defendía la idea de un arte escénico autosuficiente y plenamente autónomo donde la creación no necesitase en absoluto de la figura del dramaturgo escritor de textos, y formulaba la posibilidad de un nuevo teatro no dramático sino cinético, basado en el movimiento de los volúmenes escenográficos, la iluminación y la música, pues a su juicio las palabras habían perdido en sí gran parte de su significado ("E1 arte del teatro", ed. José A. Sánchez, 83-95). En el libro La revolución del teatro, de 1909, el alemán George Fuchs, director del Teatro de Artistas de Munich, escribía acerca de una dramaturgia concebida en contra de la literatura y donde el movimiento y la música se antepusieran a la palabra (ed. José A. Sánchez, 211216). Directores expresionistas como Felix Emmel (Teatro extático, 1924, ed. José A. Sánchez, 234-241) recurrieron en sus puestas a toda una serie de técnicas de reteatralización - máscaras, escenografías deformadas, gestualidad distorsionada - como rechazo a la tradición del naturalismo psicológico y en busca de "un mero mostrar visionario del destino del hombre en movimiento", "el sentido fatídico, la corriente subterránea de toda realidad" (235), un "teatro mágico, cuyo flujo al mismo tiempo nos encienda y con una necesidad rítmica despierte en nosotros la conciencia del destino" (236) y domine "nuevamente un pathos de la sangre, no una hueca retórica patética" $(237)^{4}$. Junto con los anteriores, a la lista de renovadores teatrales en cuya tradición rupturista hemos de situar a $\mathrm{Ar}$ taud — con más o menos afinidades según el caso- hay que añadir asimismo a figuras como Adolphe Appia, Marinetti, Frederick Kiesler, Ivan Goll, Maiakovski, Brecht, Piscator o Meyerhold, entre otros. Y ya antes que todos ellos, el que Artaud reivindicará como uno de sus referentes fundamentales: Alfred Jarry y su Ubu rey, escenificado en 1898.

Tomando en consideración todo este complejo horizonte como base general, y centrándonos ya en el contexto específico que nos compete, no será sin embargo, como ya adelantábamos, hasta mucho más tarde, a finales de los años cincuenta y principios de los sesenta, cuando en la dramaturgia latinoamericana comience a registrarse un interés de relieve por las teorías teatrales artaudianas, "e incluso al principio claramente como fenómeno concomitante de la recepción de aquellas formas de teatro de vanguardia llamado 'del absurdo"' (Blüher, 120), cuyos principales representantes (Beckett, Ionesco, Adamov o Genet,

3 Véase a este respecto y como referencia de todo lo que sigue la "Introducción" y el trabajo recopilatorio de José A. Sánchez, que agrupa diversos manifiestos y textos de enorme interés sobre el teatro de la época de las vanguardias.

${ }^{4}$ Las similitudes entre estas ideas del Teatro extático (1924) y las propuestas de Artaud en los años 30 son más que evidentes. 
entre otros) sí enlazaban en cambio de modo directo con las concepciones dramáticas de Artaud. Bajo esa influencia absurdista se ha incluido a autores hispanoamericanos como Emilio Carballido y Elena Garro en México, Jorge Díaz en Chile, Virgilio Piñera y José Triana en Cuba, o Eduardo Pavlovsky y la propia Griselda Gambaro en Argentina, por citar a algunos de los más relevantes; y, en efecto, también en el teatro de estos dramaturgos se han tratado de rastrear vinculaciones diversas con las propuestas de Artaud, en mayor o menor medida - y con mayor o menor acierto y rigor- según el caso.

Ahora bien, como podremos comprobar con el ejemplo concreto de Gambaro, esas supuestas similitudes y/o influencias artaudianas, a menudo planteadas de manera muy genérica (en razón principalmente del uso de elementos no verbales, la importancia de la gestualidad, la estética antirrealista, el rechazo de lo psicológico, o también, ya lo veremos, partiendo de una interpretación cuanto menos discutible del término clave "crueldad"), son justamente concurrentes - e incluso a veces hasta más claramente relacionables - con ese "teatro del absurdo" que serviría de catalizador (y, en última instancia, con todo el conglomerado de ideas que están detrás del movimiento de renovación antinaturalista al que antes nos referíamos). De ahí que se haga necesario, al menos en referencia a este conjunto de dramaturgos - y así lo haremos a continuación con la obra de Griselda Gambaro - redimensionar, contrastar, reconsiderar y relativizar toda afirmación precipitada acerca de la influencia de Artaud y su teatro de la crueldad en tal o cual pieza dramática, en tal o cual autor.

\section{La dramaturgia neovanguardista de Gambaro en el contexto argentino}

Reconocida hoy internacionalmente como una de las figuras señeras del teatro latinoamericano contemporáneo, la obra dramática de Griselda Gambaro (Buenos Aires, 1928) es un ejemplo paradigmático de la perfecta simbiosis entre compromiso ético y estético, instauradora de una lúcida y personalísima visión sobre los abusos de poder y la violencia que signan las relaciones humanas y que han marcado la historia de la Argentina contemporánea. Una visión cuyo enfoque y cuya proyección trascienden con mucho los límites de esa realidad de referencia inmediata para alcanzar, como todas las grandes manifestaciones artísticas, dimensiones plenamente universales.

La labor creativa de Griselda Gambaro se ha desarrollado siempre al margen de grupos o escuelas, y, en contraste con lo que fue común entre muchos de los dramaturgos coetáneos, la autora ha tendido a mantenerse en una posición de relativa distancia con respecto al interior del mundo teatral. Su ruidoso y controvertido debut escénico tiene lugar en agosto de 1965, con el estreno de El desatino, representada bajo la dirección de Jorge Petraglia en la Sala del Centro 
de Experimentación Audiovisual del Instituto Torcuato Di Tella ${ }^{5}$. Este estreno se convertirá en el punto de arranque de lo que hoy conocemos genéricamente como la polémica entre "realistas reflexivos" $\mathrm{y}$ "neovanguardistas" la práctica tuvo principalmente a Gambaro como cabeza autorial visible sobre la que recayeron las críticas de los realistas.

La polémica se desata cuando la revista Teatro $X X$, dirigida por Kive Staiff, concede a El desatino el premio a la Mejor Obra de Autor Argentino Contemporáneo. Inmediatamente después dos de los redactores de la publicación renuncian por oposición a la resolución del jurado, y comienza un fuego cruzado entre los defensores y los detractores de una y otra tendencia. Gambaro fue acusada de formalista y de ajena a la realidad social y política de la Argentina, algo que a la distancia no deja de llamar la atención, pues prácticamente todas sus obras desde los sesenta hasta entrados los ochenta tienen como eje temático central la violencia ejercida desde diferentes instancias de poder. $Y$ de hecho, si uno revisa la bibliografía sobre el teatro de la autora, se comprueba enseguida que hay un predominio muy significativo de los estudios que privilegian la relación con el contexto histórico-político como mecanismo de acercamiento a los textos.

Las razones que explican aquella consideración inicial han sido ya convenientemente explicadas, y tienen que ver sobre todo con una serie de prejuicios vinculados a una época muy marcada por la politización y a una tradición teatral fuertemente anclada en el realismo. Con el tiempo quedó cada vez más claro, tanto para la crítica como para los propios protagonistas de la polémica, que lo que verdaderamente enfrentaba a Gambaro con autores como Roberto Cossa o Ricardo Halac no era una oposición entre dramaturgos comprometidos y no comprometidos con la Argentina, sino entre dos modos distintos de entender y de afrontar ese compromiso con la realidad y con el teatro. Aunque sin referirse explícitamente a la polémica del sesenta, Gambaro dejó constancia de su visión acerca de esta cuestión de la función social del dramaturgo en un texto de 1972, publicado en la revista Talía con el título "Por qué y para quién hacer teatro":

5 E1 Di Tella, como se lo conocerá popularmente, fue el núcleo por excelencia de las vanguardias artísticas del Buenos Aires de los años sesenta.

6 Soledad para cuatro (1961), de Ricardo Halac, está considerada obra inaugural del "realismo reflexivo", cuyos componentes más destacados fueron, junto con Halac, Roberto Cossa, Carlos Somigliana, Germán Rozenmacher y Ricardo Talesnik. Su propuesta teatral toma ciertos elementos de la estética realista de las décadas precedentes, pero refuncionalizándolos y reelaborándolos a través de la incorporación de nuevos recursos procedentes del neorrealismo norteamericano, y muy especialmente de la textualidad de Arthur Miller, ampliamente difundida en Buenos Aires desde los años cincuenta. Buscaban una dramaturgia que reflejase los avatares conflictivos de la existencia del argentino medio. Los protagonistas predilectos de los "realistas reflexivos" eran personajes mediocres, incomprendidos, inadaptados y fracasados, ligados a dramas cotidianos, familiares y personales y enfrentados a un entorno social hostil.

7 La polémica del sesenta ha sido ampliamente estudiada y documentada por Pellettieri (336-347). 
No está en la naturaleza del teatro ser políticamente revolucionario, es una expresión vital y no se encuentra separada de los conflictos como para dar respuesta: está en medio del conflicto. [...] la respuesta del teatro a los conflictos (sean sociales, políticos, humanos) es apasionada e implícita, no didáctica. No puede cambiar las estructuras sociales o políticas, y esta imposibilidad no es un tanto en contra del teatro, las estructuras se cambian con la acción social o política, y creo que si uno piensa a tal punto que la salvación o la vitalidad del teatro dependa de que tenga influencia en el cambio de estructuras, debe abandonar el teatro y acelerar ese cambio por otros medios. [...] Toda creación es un acto de adhesión y de rechazo a la cultura, de adhesión y de rechazo al medio porque es un re-ordenamiento de la realidad. $Y$ es a este nivel que el teatro es profundamente revolucionario (4-5).

Si bien el "realismo reflexivo" supuso ya un avance con respecto al didactismo “ingenuo" y directo de la tradición realista anterior, seguía subyaciendo a sus textos una concepción didáctica y testimonial de la función del teatro, materializada más o menos visiblemente en el "mensaje" o "tesis" de la obra ${ }^{8}$. Gambaro cortaba de lleno con esos conceptos y exigía en consecuencia a un receptor plenamente emancipado. En su teatro ya no había conclusiones previamente construidas, sino un lúcido y apasionado "estar dentro del conflicto". Su particular mirada, ese "re-ordenamiento de la realidad" que conforman sus piezas, pasaba además, necesariamente, por una ruptura con los moldes del realismo, y muy especialmente con esa especie de dogma según el cual el reflejo fiel de una sociedad había de quedar representado bajo el paradigma de "lo cotidiano":

Si tuviera que definir lo que es el teatro argentino de vanguardia, diría que es el esfuerzo de unos pocos autores o grupos de teatro por romper con las formas deterioradas del teatro naturalista, por reencontrar un teatro y una imagen nuestras por encima de una transcripción pedestre de la realidad que sólo nos expresa en nuestra dimensión más mínima (Gambaro 1970, 309).

Hay que aclarar, sin embargo, que ni Gambaro rechazaba a todos los autores realistas - Chejov era y ha seguido siendo uno de sus dramaturgos predilectos-, ni desde luego defendía cualquier intento de renovación o de experimentación por el mero hecho de romper con el realismo9. Es que estas

8 A este respecto, véase Pellettieri, 244-306.

9 Y esto es muy evidente, por ejemplo, si seguimos leyendo el escrito de 1972 antes citado: "Lo que está agotado no son las posibilidades escénicas que brinda el teatro a la italiana, es que muchos achacaban al teatro a la italiana sus propias carencias para expresar un mundo contemporáneo o un mundo que despierte al hombre contemporáneo, y entonces, se cree que modificando el espacio escénico, o usando sillas movibles, o aullidos, o interpelaciones directas al espectador, se quiebra la barrera y se responde al espíritu de la época. La experimentación es una ventana abierta que trae aire, pero la casa está hecha. Y la casa no es el teatro sino la necesidad del hombre de hacer teatro. Por eso, lo que importa no son los medios técnicos, o que los actores caminen por la sala o interpelen al público, sino otra cosa. No es decidirse a priori por un teatro pobre o un teatro 
palabras están pronunciadas en un contexto, el de los sesenta y setenta, donde, repetimos, la herencia realista pesaba como una losa sobre la dramaturgia. Y aunque este hecho era especialmente ostensible y se manifestaba con caracteres propios en la Argentina, tampoco fue desde luego privativo de aquel momento ni de aquel lugar. Como ya apuntábamos en parte en el apartado precedente, casi todas las propuestas del teatro europeo que, desde finales del siglo diecinueve hasta los años sesenta, han caído de un modo u otro bajo el rótulo "vanguardia”, tienen que ver con modos diversos, a veces incluso antagónicos, de romper con la tradición dramática mimético-ilusionista. Y es que, por su peculiar modo de recepción, en el teatro, mucho más que en otros géneros, nunca se ha terminado de ganar el pulso a la hegemonía realista.

Los procedimientos que Griselda Gambaro emplea en su personal versión de este pulso son los que han venido a configurar los principales rasgos de lo que hoy estudiamos como su teatro de "neovanguardia" (1963-1974), caracterizado por una densa metaforicidad en abierta confrontación con los moldes convencionales del realismo. Se trata de textos que articulan entramados simbólicos que, si bien inscritos en coordenadas racionales muy poderosas, construyen una co-realidad autónoma, exasperada y desligada de lo cotidiano, cuyos anclajes referenciales aparecen velados, deformados, diferidos. La lógica causal de los conflictos tiende a permanecer deliberadamente implícita y opacada, sin que lleguen a aclararse mínimamente las motivaciones que explican el comportamiento de muchos personajes. Los acontecimientos previos al presente de la obra participan igualmente de esta vaguedad: o directamente no se nos aporta dato alguno acerca de la "prehistoria", o bien ésta aparece teñida de confusión, enigmática y esencialmente ambigua. Otro tanto sucede con los desenlaces, casi siempre cercenados, imprecisos, irresueltos en un sentido tradicional, rompiendo con el deseo de verificación del público. Los protagonistas de este universo dramático son seres por lo general anti-catárticos y carentes de complejidad o profundidad psicológica, cuyo enfrentamiento se vehicula a través de situaciones predominantemente estáticas, basadas en la dislocación de los procesos comunicativos y en la modulación de una tensión sostenida y progresivamente exacerbada. Y es de este teatro "neovanguardista" de donde ha partido la crítica para plantear, con más o menos matizaciones, tanto la influencia del "teatro del absurdo" europeo en la obra de Gambaro ${ }^{10}$, como — aunque en menor medida, y con los problemas que iremos viendo a continuación - las posibles vinculaciones entre la dramaturgia gambariana y las teorías teatrales de Artaud.

con texto o sin él. Lo que importa es el estilo, la respiración de un autor o director o conjunto, y que nace de aquella primera necesidad de expresión" (6).

10 La adscripción absurdista del teatro "neovanguardista" de Griselda Gambaro ha sido también una cuestión ampliamente comentada y discutida por la crítica especializada. Para un panorama general al respecto, véase el trabajo de Tarantuviez (204-214). 


\section{Gambaro y el teatro de la crueldad artaudiano: estado de la cuestión}

Comencemos por repasar las referencias críticas más destacadas en cuanto a las relaciones de similitud o parentesco entre el teatro de la crueldad artaudiano y la concepción dramática de Griselda Gambaro, para luego deslindar, revisar, discutir y contrastar más detenidamente los alcances específicos de esas relaciones en sus aspectos concretos, tomando como punto de partida todo el panorama general apuntado en los apartados precedentes.

El primer trabajo de cierto relieve - luego citado repetidamente por la crítica posterior- en el que se vincula a Gambaro con Artaud, en 1970, es el de Tamara Holzapfel, que precisamente alude a este influjo artaudiano como parte de un análisis que encuadra las primeras piezas de la autora dentro del "teatro del absurdo”, en la línea de esa recepción mediada que comentábamos anteriormente. Según señala Holzapfel, de las cinco obras teatrales que Gambaro había compuesto hasta el momento, las tres más importantes a su juicio - El desatino y Los siameses, escritas en 1965, y El campo, de 1967- constituían un testimonio de la influencia de "Antonin Artaud whose theoretical writings and staging experiments prepared the way for the French Theatre of the Absurd" (5), en razón del cumplimiento de tres requisitos básicos que Holzapfel marca como centros de la reflexión teórica de El teatro y su doble: el uso de un nuevo lenguaje en el teatro; la catarsis, incorporando la idea de crueldad y del doble; y el sentido casi mítico de la vocación que la puesta en escena debe tener. Griselda Gambaro escribe Holzapfel- cumpliría con estos tres postulados nucleares mediante el uso de un lenguaje no retórico e integrado con gestos y sonidos de todo tipo, incorporando la crueldad psicológica y la violencia física, y asignando una importancia de primer orden a la puesta en escena (5-6) ${ }^{11}$.

En 1975, Sandra M. Cypess aborda el asunto más ampliamente y, ahora sí, planteándose como propósito específico ofrecer "a detailed examination of the four available plays of Gambaro in relation to the Artaudian theories on the importance of physical imagery on stage" (357). Las cuatro piezas teatrales a las que se refiere son Las paredes (1963) - la primera obra dramática de Gambaro-, El desatino, Los siameses y El campo, y centra su análisis en el uso de la gestualidad y el movimiento, la manipulación del espacio físico, de los objetos y de la sonorización, y la construcción de un lenguaje teatral no-verbal en escena. Cypess vincula el manejo de estos elementos con las ideas de Artaud,

11 El planteamiento de Holzapfel, que en todo caso cuenta con la dificultad de encontrarse en un momento aún muy temprano en relación con los estudios del teatro de Gambaro - de hecho es de los primeros análisis críticos que se hacen de su obra, con todo lo que ello implica-, es muy discutible por muchos motivos, como luego iremos viendo. Pero, como señalábamos al comienzo de este epígrafe, comenzamos por exponer únicamente las diferentes afirmaciones de la crítica acerca de la cuestión, para, después de trazar ese panorama completo, ir contrastando y discutiendo punto por punto cada aspecto concreto del asunto. 
concluyendo que Griselda Gambaro "has assimilated his theories and integrated them into her own theatrical art" (358).

Varios años después, al comienzo de su estudio sobre El campo, publicado en 1980, Evelyn Picón Garfield retoma las ideas de Holzapfel y Cypess, pero esta vez problematizando ya un aspecto concreto en torno a la influencia de Artaud en el teatro de Gambaro que, como iremos viendo, es precisamente uno de los principales puntos de divergencia después señalados con frecuencia por la crítica: "Como lo notaron Holzapfel y Cypess, unas técnicas propuestas por Antonin Artaud funcionan eficazmente en el teatro de Gambaro: sonidos, gestos, movimientos, luces, gritos, onomatopeya, objetos visuales, subrayan una propiedad dramática, no literaria de su teatro. A pesar de la importancia de la riqueza de esos sistemas dramáticos, no se disminuye el valor de la palabra hasta el punto que recomienda Artaud" (95).

En otoño de ese mismo año 1980 sale a la luz un interesante artículo de Rosaela Postma, "Space and Spectator in the Theatre of Griselda Gambaro: Información para extranjeros", donde esta obra de Gambaro en particular, Información para extranjeros (1973) - excepcional por otra parte dentro de su producción-, se relaciona por su espacialización rupturista y transgresora, supresora de la división entre escenario y sala, con la propuesta de Artaud en El teatro y su doble (97, 109) acerca de un espectáculo giratorio situado en un lugar único, sin obstáculos que separen al espectador de la acción, y con el uso de sillas móviles que permitan al público seguir lo que sucede a su alrededor: "she executes her subversive thrust in Informacion as the spectator, unable to withdraw from the action, becomes a necessary part of the events. This is one of the Artaudian techniques of Informacion: Artaud actually wrote of a theatre in which the audience would follow the spectacle on mobile chairs and the spectator would be engulfed by the action" (Postma, 40).

Durante los años siguientes aparecen algunas menciones más a la cuestión, si bien por lo general dentro de trabajos que se centran más bien en otros aspectos, y, por tanto, sin una profundización ni un estudio detenido y riguroso que sostenga o justifique suficientemente las afirmaciones. Así en el estudio de Karen L. Laughlin "The Language of Cruelty: Dialogue Strategies and the Spectator in Gambaro's El desatino and Pinter's The Birthday Party" (1986), que, frente al problema de la importancia de la palabra en el teatro de Gambaro en contraste con su rechazo por parte de Artaud, señala que "the linguistic maneuvering characteristic of Gambaro's plays does not necessarily undermine the connection between her work and Artaud's theories. Rather, a basic cruelty underlies the very words of Gambaro's characters and this in turn brings us back to Artaud's demand for 'extreme action, pushed beyond all limits, and to his notion of a Theatre of Cruelty" (12). A ese mismo supuesto punto de enlace a través de la noción de "crueldad" aludirá en 1990 Linda S. Zee (604). 
La crítica a partir de los noventa va a tender sin embargo bastante más frecuentemente no a defender sino a cuestionar diferentes aspectos de esas posibles conexiones entre los postulados artaudianos y la dramaturgia gambariana. Fernando de Toro es uno de los casos más elocuentes al respecto, con su impugnación acerca de la interpretación errónea y desvirtuada del concepto de "crueldad":

Se ha clasificado a Griselda Gambaro como artaudiana por presentar un teatro de la crueldad a nivel de contenido (y no a nivel de significante, que de hecho es donde se sitúa la propuesta de Artaud), pero, otra vez, se trata de una deformación de la dramaturgia gambariana [...]. Es aquí donde la mirada prejuiciada del crítico (a través de Artaud), desvirtúa el origen de la crueldad gambariana, que procede de la victimización que toda una sociedad sufre pasivamente, sin rebelarse. Es esto lo que Gambaro ataca y subvierte a través de la crueldad. Esto es, confronta al espectador con la crueldad que se vive en su propia sociedad y en su propio entorno inmediato. Pero, una vez más, es este contexto el que determina los actos de crueldad [...] y no una estética artaudiana. Debe señalarse que la propuesta artaudiana tenía que ver fundamentalmente con la puesta en escena, con la construcción de una nueva espectacularidad, y no de una dramaturgia, como es el caso de Gambaro. La crítica ha confundido el contenido dramatúrgico de Gambaro con la escenificación artaudiana; de ahí el error (36-37).

De Toro añade además otra objeción fundamental, ligada también a esa "crueldad" artaudiana en su dimensión metafísica, y apelando a algo que la crítica anterior parecería haber pasado por alto o tomado a la ligera - y que precisamente falta en el teatro de Griselda Gambaro-: el sentido de la ritualidad, ya que "los problemas que se planteaba Artaud [...] nada tienen que ver con el problema de la opresión, de la tortura, del silencio y la soledad en que ha vivido todo un pueblo por décadas", y lo que en cambio preocupaba al autor de El teatro y su doble era "recuperar la teatralidad, el sentido ritual y sagrado del teatro, su origen catártico perdido en Occidente" (37).

Ane-Grethe Ostergaard pone de manifiesto este mismo problema al principio de su trabajo sobre la semiótica del diálogo en El campo:

Dentro de la crítica bastante amplia que hasta ahora se ha realizado sobre la obra dramática de Griselda Gambaro se hace notar la palabra "crueldad", repetida una y otra vez. Parece existir entre los críticos la opinión unánime de la crueldad como tema central y constante, y en varios trabajos se ve clasificada la obra de Griselda Gambaro dentro del teatro de la crueldad de inspiración artaudiana. Estamos de acuerdo en la observación de la crueldad como tema que bajo diversas formas sigue preocupando a la autora, pero no apoyamos dicha categorización [....] porque la idea desarrollada por Artaud sobre la crueldad no se puede captar a base de un concepto cotidiano de lo cruel, como lo hacen algunos críticos (267). 
Ostergaard alude asimismo a la ya mencionada cuestión del lenguaje verbal, anotando cómo el teatro de Gambaro "aunque quizás se haya inspirado en la teoría de Artaud en cuanto a un uso extenso de efectos físicos, no-literarios, no nos parece corresponder a la idea de Artaud con lo que respecta al papel de la palabra, apreciada por Artaud sólo por sus cualidades puramente físicas: sonido, entonación, vibración en el espacio" (268). En una línea crítica semejante, Marta Contreras, en 1994, recupera nuevamente el tema de la ritualidad como piedra de toque, pues si bien las piezas gambarianas "contienen múltiples escenas de crueldad física o emocional" estas escenas no son sin embargo "levantadas para provocar en una relación ritual con la representación una transmutación en el espectador sino que son expuestas como posibilidades reales del mundo doméstico y familiar que vivimos desprovistas de todo valor ritual o sagrado" (18). Más recientemente, Susana Tarantuviez, en su completo estudio de conjunto sobre el teatro de Gambaro, publicado en 2007, parte de una panorámica general sobre los aportes críticos anteriores para establecer sus propios juicios y matizaciones. Como puntos de contacto entre las ideas de Artaud y la dramaturgia de Gambaro señala el rechazo del teatro psicológico de corte naturalista (200), la defensa de un teatro "no hedonista, que no fuera una diversión inútil ni puro entretenimiento" (201), el uso del espacio en Información para extranjeros, en términos muy semejantes a los que planteaba Postma (201), y, desde una perspectiva más genérica, el carácter transgresor que ambos comparten (199). No obstante, Tarantuviez hace sobre todo hincapié en aquello que, en cambio, separaría claramente una y otra propuesta: Gambaro "no adhiere a la desliteraturización del teatro", "nada más alejado de la concepción del hecho teatral en Gambaro, quien defiende su creación en tanto escritora" (199); "el de Gambaro no es un teatro catártico como el que propone Artaud, sino que produce distanciamiento y conduce a la reflexión" (203); y "no basta con textualizar la violencia para que se trate del 'teatro de la crueldad' artaudiano, pues lo que prima en la propuesta de Artaud es un concepto ritual con un trasfondo de crueldad o violencia, y no a la inversa" (203); por lo que "la textualidad de Gambaro definitivamente no puede ser adscrita" al "teatro de la crueldad de inspiración artaudiana" (199).

\section{Artaud en Gambaro: revisión, deslinde y posibles alcances}

Dentro del panorama esbozado en el apartado precedente ha quedado por mencionar un aporte crítico fundamental que, por su importancia y particularidad, cabe separar del resto y nos hemos reservado hasta ahora. Nos referimos al estudio de Blüher con cuya mención abríamos este trabajo. Más allá de las afirmaciones del crítico respecto al caso de Gambaro como receptora de Artaud (muy breves y bastante semejantes a algunas de las que mencionábamos arriba, limitándose a señalar la presencia de "elementos no verbales del texto espectacular, del lenguaje visual del espacio escénico, de lo gestual y los objetos y de los 
signos acústicos" empleados con una nueva función "que se deriva [...] de los conceptos de Artaud", 120-121), lo que realmente nos interesa de este artículo es que recoge unas palabras de la propia Griselda Gambaro - tomadas de una carta escrita a Bluhër en junio de 1989- en referencia directa a la cuestión que estamos tratando ${ }^{12}$ :

En lo que a mí respecta diría que Artaud ha alimentado, con otros, el impulso transgresor que debe tener toda obra. Lo que me interesa es su idea de la cultura en acción, su ampliar límites, ese deseo irreprimible de libertad, su inmersión en el sueño, su rechazo de la cotidianeidad empobrecida. Yo tomo de Artaud esa pasión de desestructuración de la cultura, ya que la cultura (el teatro) tiende a fijarse en sus resultados, y esto es precisamente lo que ocasiona su muerte. Otros criterios de Artaud los tomo selectivamente. Yo, que soy autora, creo en la palabra como una invalorable necesidad, nunca palabra escrita (aunque lo sea en el texto) sino palabra-acción, palabra-gesto, lo que no cierra el camino a su valor significativo, ya que para mí forman teatralmente una sola entidad. Siempre le agradezco que nos ponga sobre aviso respecto a la construcción insensible, la forma vacía, ese valor de 'reacción' que tiene su discurso, surgido precisamente frente al teatro francés de su época, racional, discursivo, 'cuidado'. El peligro es dogmatizar a partir de Artaud [...]. Por ejemplo, cuando dice: 'Las obras maestras son buenas para el pasado, pero no para nosotros', sólo tomo de esta aserción lo que subraya mi contemporaneidad, pero personalmente estoy lejos de oponerme al pasado, ya que el intercambio entre originalidad y aceptación de una tradición constituye la base de la capacidad de inventar (cit. Blüher, 121).

Estas palabras de Gambaro proporcionan un buen punto de partida para comenzar con la revisión, el deslinde y la valoración de su recepción de las ideas de Artaud y de la medida en que éstas han podido ejercer una cierta influencia sobre determinados aspectos de su concepción dramática.

En primer lugar, desde una perspectiva amplia - y según ya apuntaba brevemente Tarantuviez (199) refiriéndose precisamente a estas declaraciones-, tanto Artaud en El teatro y su doble, como Gambaro en sus piezas "neovanguardistas", ponen de manifiesto una actitud transgresora en oposición al teatro vigente en sus contextos respectivos - el teatro francés de los años veinte y treinta, paradigma de los vicios del teatro occidental; el teatro argentino de los cincuenta y sesenta-, en ambos casos dominado por el imperio de una estética de corte realista y contenido psicológico. “¿Quién ha dicho que el teatro se creó para analizar caracteres, o resolver esos conflictos de orden humano y pasional, de orden actual y psicológico que dominan la escena contemporánea?”, se había preguntado Artaud (46), proponiendo como revulsivo a ese "teatro occidental

12 Una cuestión que, frente a lo que sucede en el caso del "teatro del absurdo", apenas ha aparecido curiosamente en las numerosas entrevistas realizadas a la autora, de ahí el interés de estas declaraciones en concreto. 
de tendencias psicológicas" (50) un nuevo concepto vital del arte como "cultura en acción", liberado de sus convencionalismos y que desautomatizase la percepción natural-objetivista de la vida cotidiana (Dubatti, 74). Esta desautomatización rupturista de la mirada convencional - ya lo veíamos - va a ser básica también en las propuestas dramatúrgicas gambarianas, que comparten ese espíritu artaudiano de desestructuración de los valores culturales imperantes y de trascendencia del concepto empobrecido de la cotidianeidad (recordemos por ejemplo esa alusión de Gambaro, en su definición del teatro argentino de vanguardia, a las "formas deterioradas del teatro naturalista" y a la necesidad de superación de la "transcripción pedestre de la realidad que sólo nos expresa en nuestra dimensión más mínima”, 1970, 309).

No obstante, todo este "impulso transgresor" anti-realista, tal como lo hemos descrito, no pasa de ser un concepto genérico que, si de un lado permite realizaciones concretas muy diversas e incluso antagónicas - y diversas serán las plasmaciones de Gambaro con respecto a las de Artaud-, de otro no puede ser en ningún modo atribuido de manera exclusiva a la influencia de Artaud, pues, como ya comentábamos atrás, forma parte de un movimiento mucho más amplio de renovación teatral que implica a numerosas corrientes y autores; y ahí tenemos de hecho la referencia de Gambaro a ese "con otros" que acompaña a todo lo que "Artaud ha alimentado". Enseguida también la puntualización: "otros criterios de Artaud los tomo selectivamente"; de modo que a ese criterio selectivo, parcial y, como veremos, limitado en muchos aspectos, queda sujeto todo el grueso de las propuestas ya específicas de El teatro y su doble. La primera en pugna: la palabra. "Yo, que soy autora, creo en la palabra como una invalorable necesidad”, dice Gambaro, corroborando lo que ya habíamos visto señalado por Picón Garfield, Ostergaard o Tarantuviez.

En este punto sería conveniente detenerse a considerar brevemente qué es en concreto lo que se va a ir exponiendo en El teatro y su doble respecto del papel de la palabra en las artes escénicas. Tomemos como referente inicial una de las preguntas fundamentales que se hace Artaud y que, en tono acusatorio, lanza a su vez a los lectores: “¿Cómo es posible que el teatro, al menos tal como lo conocemos en Europa, o mejor dicho en Occidente, haya relegado a último término todo lo que es específicamente teatral, es decir, todo aquello que no puede expresarse con palabras, o si se quiere todo aquello que no cabe en el diálogo, y aun el diálogo como posibilidad de sonorización en escena, y las exigencias de esa sonorización?” (41).

Lo "específicamente teatral" se definiría en principio, entonces, en oposición al lenguaje hablado de la palabra que ha sido el centro del teatro occidental, pues "la escena es un lugar físico y concreto que exige ser ocupado, y que se le permita hablar su propio lenguaje concreto" y ese lenguaje concreto debe estar "destinado a los sentidos" y es por tanto "independiente de la palabra"; un "lenguaje físico y concreto" que "no es verdaderamente teatral sino en cuanto expresa 
pensamientos que escapan al dominio del lenguaje hablado" (42). Como es sabido, Artaud encuentra un modelo de referencia para ese "lenguaje teatral puro, que no necesita de la palabra" en el teatro balinés, donde "toda creación nace de la escena, encuentra su expresión y hasta sus orígenes en ese secreto impulso psíquico del lenguaje anterior a la palabra" (68).

Ahora bien, este rechazo aparentemente frontal del lenguaje hablado como ajeno a lo específicamente teatral — que desde luego chocaría de lleno con las propuestas dramáticas de Gambaro, donde el uso de la palabra es absolutamente central - ha de ser entendido - y relativizado-, primero, en relación - y en oposición - a ese contexto en el que "para el teatro occidental la palabra lo es todo, y sin ella no hay posibilidad de expresión; el teatro es una rama de la literatura" (Artaud, 79); y, segundo, especialmente, en la medida en que el propio Artaud matiza y redimensiona estas afirmaciones a lo largo de El teatro y su doble. "No se trata", aclarará Artaud, "de suprimir la palabra en el teatro; sino de modificar su posición, y sobre todo reducir su ámbito, y que no sea sólo un medio de llevar los caracteres humanos a sus objetivos exteriores, ya que al teatro sólo le importa cómo se oponen los sentimientos a las pasiones y el hombre al hombre en la vida"; emplear la palabra "de un modo concreto y en el espacio, combinándola con todo lo que hay en el teatro de espacio y de significativo, en el dominio concreto" (83); utilizar "la palabra como una fuerza activa, que nace de la destrucción de las apariencias" (81); "hacer que el lenguaje exprese lo que no expresa comúnmente", "emplearlo de un modo nuevo, excepcional y desacostumbrado", "devolverle la capacidad de producir un estremecimiento físico (5152); huir de "la obsesión por la palabra clara que lo exprese todo" (134).

A diferencia de lo que señalaba Susana Tarantuviez (Gambaro "no adhiere a la desliteraturización del teatro", 199) sí creemos que Griselda Gambaro comparte con Artaud (y "con otros"), hasta cierto punto, ese deseo de "desliteraturizar" y "reteatralizar" el teatro, en busca de una palabra refuncionalizada que no sea meramente literaria sino específicamente constituida de acuerdo con su dimensión espectacular; no pensada como transmisión de una psicología, ni desde luego como transcripción directa de una ideología de autor - funcionamiento típico de la dramaturgia "de tesis" realista—, sino concebida para la representación e imbricada en todo un lenguaje específicamente escénico, "de un modo nuevo, excepcional y desacostumbrado"; desligada de los rígidos parámetros de la expresión de la cotidianeidad y de la "obsesión por la palabra clara"; "fuerza activa" destructora de las apariencias. Así lo apunta Gambaro en las declaraciones en referencia a Artaud citadas por Blüher ("nunca palabra escrita (aunque lo sea en el texto) sino palabra-acción, palabra-gesto, lo que no cierra el camino a su valor significativo", 121); así lo había manifestado ya mucho antes en sus reflexiones acerca del teatro argentino de vanguardia ("A nadie le interesa ya un teatro literario, pero desconfiar de la palabra y anularla como elemento expresivo, es ahogar tontamente una riqueza. [...] Quizás lo que debamos aprender, sobre todo los 
autores argentinos que hemos usado siempre el lenguaje como intermediario de vivencias, es a usar ese lenguaje como elemento teatral, palabra-acción, signo articulado que se ofrezca desnudo en acción teatral”, 1970, 328-329); y así sucede en efecto en su producción dramática de "neovanguardia". Una refuncionalización que, sin embargo - he aquí uno de los focos de divergencia esencialestransita en su plasmación gambariana concreta por caminos bastante diversos a los que plantea ya algo más específicamente Artaud (dentro de la ambigüedad que, en todo caso, envuelve a muchas de las ideas de El teatro y su doble).

Esa palabra puramente teatral, no suprimida pero sí modificada y reducida en su ámbito, tiene que ver directamente en Artaud con la construcción de una "metafísica del lenguaje hablado", vuelto en contra de "sus fuentes bajamente utilitarias" y considerado "como forma de encantamiento", reencontrando "el significado religioso y místico que nuestro teatro ha perdido completamente" (52); una palabra manejada "como un objeto sólido que perturba las cosas, primero en el aire, y luego en un dominio más secreto e infinitamente más misterioso" (83), rota la "sujeción intelectual del lenguaje, prestándole el sentido de una intelectualidad nueva y más profunda que se oculta bajo los gestos y bajo los signos elevados a la dignidad de exorcismos particulares" (103). "Se trata de sustituir el lenguaje hablado por un lenguaje de naturaleza diferente con posibilidades expresivas equivalentes a las del lenguaje verbal, pero nacidas en una fuente mucho más profunda, más alejada del pensamiento" (124), devolviendo "al lenguaje de la palabra su antigua eficacia mágica, su esencial poder de encantamiento, pues sus misteriosas posibilidades han sido olvidadas" (126). Hacer "que las palabras sean oídas como elementos sonoros y no por lo que gramaticalmente quieren expresar" (135). Y aunque podrá haber "lenguaje hablado, expresiones verbales explícitas en todas las partes claras y netamente dilucidadas de la acción", "junto con ese sentido lógico, se dará a las palabras su sentido verdaderamente mágico” (142).

La "palabra-acción" que propone Gambaro y que se realiza en su teatro no tiene nada que ver con este uso mágico, religioso, místico y "desvelador de misterios de dominios secretos" del lenguaje, concepciones que son del todo ajenas a los intereses de la autora. De hecho, Gambaro nunca llega a romper verdaderamente con los usos occidentales de la palabra — aunque sí rompa con el manejo que de ella hacía el teatro realista - o con la sujeción intelectual última del lenguaje, pese a que sus personajes sí contravengan esa sujeción al estar construidos muy frecuentemente en base a un comportamiento donde, por ejemplo, las contradicciones entre gestos, acciones y diálogos son constantes. Pero es que es precisamente esa inconsecuencia —entendida como claramente negativauno de los puntos donde estriba su carácter crítico, su dirección reflexiva y su deseo de poner en evidencia el poder, no "mágico", sino ético y social, del lenguaje, de la palabra como mecanismo opresivo de engaño y manipulación de los hechos, o también, en el polo opuesto, como arma de rebelión, toma de conciencia 
y puesta al descubierto de verdades silenciadas. Algo muy alejado, de nuevo, de los preceptos del teatro de la crueldad; pues en última instancia lo que encontramos son dos planteamientos muy distintos acerca de la función de lo teatral, según comentaremos a continuación.

Si bien es cierto que, como había hecho notar Tarantuviez (201), tanto en Gambaro como en Artaud hay una voluntad imperativa de superación de lo meramente lúdico en el teatro, creando un arte no hedonista que quiebre el horizonte de expectativas de lo espectacular como diversión intrascendente ("un teatro serio que trastorne todos nuestros preconceptos”, Artaud, 95), mientras que las obras de la dramaturga argentina ponen el acento sobre la dimensión moral y social del hombre, el teatro metafísico que propugna Artaud se propone entre otras cosas precisamente trascender esa dimensión con una "acción verdadera, pero sin consecuencias prácticas" que "no desborda al plano social" y "mucho menos al plano moral" (Artaud, 130) y dirigiéndose "al hombre total y no al hombre social" (140). Y así, al ideal artaudiano de alejamiento de la actualidad y de los acontecimientos (Artaud, 111), se opone la raíz fuertemente ligada a la historia argentina de la dramaturgia de Griselda Gambaro, que en su indudable proyección universal, y apartada en todo caso de cualquier matiz panfletario, está no obstante muy arraigada en el acontecer sociopolítico inmediato.

En esa misma dirección discordante, y en relación directa con lo anterior, apunta la importante cuestión de la ritualidad como núcleo de la teatralidad artaudiana; ritualidad de la que se deriva tanto la concepción mágica, metafísica y mística del lenguaje en El teatro y su doble, como el propio significado que el término "crueldad" tiene para Artaud y que ha sido repetidas veces malinterpretado al aplicarlo a las piezas dramáticas de Gambaro. Como certeramente ha señalado Nora Eidelberg, "Artaud habló de la necesidad de un lenguaje ritual y tal vez se habrían evitado muchos equívocos si hubiera titulado sus manifiestos como teatro ritual" (30). No hay en la textualidad gambariana nada equiparable a ese concepto de lo ritual al que permanentemente apela Artaud, y esto lo vieron ya claro críticos como Fernando de Toro, Ane-Grethe Ostergaard o Marta Contreras, en los términos en que quedó expuesto en el apartado precedente. $\mathrm{Ni}$ tampoco - así lo exponía Susana Tarantuviez - se puede vincular la producción de Gambaro a todo el componente catártico que va ligado a esa ritualidad.

Recordemos a este respecto cómo Artaud relacionaba su ideal de teatro con la peste, por esa capacidad terapéutica, liberadora de fuerzas, exorcisante, purificadora, drenante de "abcesos" colectivos, "azote vengador", "epidemia redentora" (35), "crisis que se resuelve en la muerte o la curación" (36), que la verdadera escena debía recuperar. Y también las innumerables referencias al teatro como ceremonia trascendente; rito metafísico "donde violentas imágenes físicas quebranten e hipnoticen la sensibilidad del espectador, arrastrado por el teatro como por un torbellino de fuerzas superiores [...]. Un teatro que induzca al trance, como inducen al trance las danzas de los derviches y de los aisaguas, y 
que apunte al organismo con instrumentos precisos y con idénticos medios que las curas de música de ciertas tribus" (94).

Nada de esa concepción sagrada, ceremonial, curativa y catártica del teatro aparece en la obra dramática de Griselda Gambaro, dominada más bien —al menos desde luego en su etapa "neovanguardista" - por una visión que empuja al distanciamiento del espectador, dirigida a la reflexión crítica además de a los sentidos y orientada a despertar en el público una toma de conciencia intelectual y ética, en modo alguno un "trance" irreflexivo. Y esta misma cuestión hace que tengamos que redimensionar también todas las afirmaciones críticas en torno a la importancia de la gestualidad, la sonoridad y el tono en el teatro de Gambaro como factores atribuidos a una influencia artaudiana.

Ciertamente, Gambaro dota a sus textos - y muy especialmente a sus textos de "neovanguardia" - de una carga enormemente prolija de acotaciones dirigidas a detallar tanto la entonación como los gestos que deben acompañar a las palabras de sus personajes. E1 dramaturgo mexicano Emilio Carballido dijo de Los siameses (1965) - y esto podría aplicarse a muchas otras piezas gambarianas- que recordaba "esos conciertos de algunos músicos para ejecutantes privilegiados y egocéntricos” (630), en razón de la centralidad y exhaustividad de las modulaciones gestuales y tonales. $Y$ en esa misma línea de un lenguaje pensado por y para la representación, también en bastantes de sus obras encontramos un uso extraordinariamente relevante de los sonidos, gritos, ruidos, etc. Pero, otra vez, esta semejanza genérica con las propuestas de El teatro y su doble - y con las de otros autores y corrientes escénicas, insistimos- se termina en el momento en que Artaud comienza a definir todos esos elementos en razón de una utilización intrínsecamente ritual, con toda una serie de especificaciones que no hallamos en los textos de Gambaro.

Esa coincidencia en las especificaciones falta también, por ejemplo, en el texto más experimental y rico en recursos técnicos de la producción de Gambaro, Información para extranjeros (1973), que, según apuntamos antes, tanto Rosaela Postma como Susana Tarantuviez han relacionado directamente con uno de los diseños de espacialización recogidos en las páginas de El teatro y su doble:

She executes her subversive thrust in Informacion as the spectator, unable to withdraw from the action, becomes a necessary part of the events. This is one of the Artaudian techniques of Informacion: Artaud actually wrote of a theatre in which the audience would follow the spectacle on mobile chairs and the spectator would be engulfed by the action (Postma, 40).

En Información para extranjeros sí parece ponerse en juego una de las técnicas artaudianas: Artaud había imaginado un teatro en el que el público siguiera el espectáculo en sillas móviles de tal manera que fuera así envuelto por la acción dramática, en la pieza de Gambaro cada grupo del público debe seguir a un guía a través de las diversas habitaciones en las que tienen lugar la acción dramática 
y, si bien nunca es obligado a participar en ella, algunos actores, mezclados con el público, producen la ilusión de un borramiento entre público y representación (Tarantuviez, 201-202).

En Información para extranjeros - que en todo caso, como hace notar la propia Tarantuviez, es una excepción en la textualidad gambariana- se golpea en efecto la sensibilidad del público despojándolo de la invisibilidad virtual asociada a su tradicional posición en el teatro, "protegido" y "escondido" tras la cuarta pared. La autora quiebra aquí la dicotomía convencional escenario-sala para colocar al espectador en el interior mismo del espacio de la violencia; una situación en la que su condición voyeurista, cómoda e implícita en el teatro tradicional, queda al descubierto y se explicita para violentarlo; en la que no sólo ve sino que es visto, y es señalado y apelado, y está expuesto a la mirada de los otros; pierde su dominio del espacio escénico, y es así presa fácil del macabro juego de revelaciones y ocultaciones que la obra articula.

Pero, ¿hasta qué punto puede realmente decirse que Gambaro "parece poner en juego una de las técnicas artaudianas"? Porque, más allá de la ruptura con la división escenario/sala y la comunicación directa que se establecería entonces entre público y espectáculo - un hecho que ha tenido manifestaciones muy diversas a lo largo de la historia teatral del siglo XX-, no hay ninguna otra concurrencia entre lo que plasma la pieza de Gambaro y lo que plantea teóricamente Artaud. Según se indica en la acotación inicial que abre el texto de Información para extranjeros, "el ambiente teatral puede ser una casa amplia, preferentemente de dos pisos con corredores y habitaciones vacías, algunas de las cuales se comunican entre sí", y "el público será dividido en grupos" conducidos por guías que irán marcando distintos itinerarios a través de cuartos y pasillos, y con ello diferentes desarrollos posibles de la acción. Lo que estos grupos van a visitar es una suerte de museo de los horrores; un escaparate de atrocidades, humillaciones, vejaciones y abusos, enmarcados muy explícitamente en un contexto de referencia directamente señalado desde el comienzo: "La pieza" — según comunica el Guía - "responde a nuestro estilo de vida: argentino, occidental y cristiano. Estamos en 1971". Veamos en cambio lo que se dice en El teatro y su doble en referencia a la posibilidad de un "espectáculo giratorio" (Artaud, 97) que suprima la separación entre escenario y sala:

Suprimimos la escena y la sala y las reemplazamos por un lugar único, sin tabiques ni obstáculos de ninguna clase, y que será el teatro mismo de la acción [...]. De modo que, abandonando las salas de teatro actuales, tomaremos un cobertizo o una granja cualesquiera, que modificaremos según los procedimientos que han culminado en la arquitectura de ciertas iglesias, de ciertos lugares sagrados $[\ldots]$. En el interior de esa construcción prevalecerán ciertas proporciones de altura y profundidad. Cerrarán la sala cuatro muros sin ningún adorno, y el público estará sentado en medio de la sala, abajo, en sillas móviles, que le permitirán seguir el espectáculo que se ofrezca a su alrededor. En 
efecto, la ausencia de escena en el sentido ordinario de la palabra invitará a la acción a desplegarse en los cuatro ángulos de la sala. Se reservarán ciertos lugares para los actores y la acción en los cuatro puntos cardinales de la sala. Las escenas se interpretarán ante muros encalados, que absorberán la luz. Además, en lo alto unas galerías seguirán el contorno de la sala, como en ciertos cuadros primitivos. Tales galerías permitirán que los actores, cada vez que la acción lo requiera, se persigan de un punto a otro de la sala [...] (109-110).

Y la descripción de ese "espectáculo giratorio" y ceremonial artaudiano sigue y sigue con toda una suerte de detalles que no se corresponden desde luego con el planteamiento espacial, funcional y retórico de Información para extranjeros. Otro tanto va a suceder, y en este caso aún más claramente, con el concepto también ritual y metafísico de la "crueldad" artaudiana, palabra empleada, como tantas veces insiste Artaud, no en su significado cotidiano, sino "en el sentido de apetito de vida, de rigor cósmico, de necesidad implacable, en el sentido gnóstico de torbellino de vida que devora las tinieblas, en el sentido de ese dolor, de ineluctable necesidad, fuera de la cual no puede continuar la vida" (116-117); pues "no se trata en absoluto de la crueldad como vicio, de la crueldad como brote de apetitos perversos que se expresan por medio de sanguinarios ademanes [...] sino al contrario, de un sentimiento desinteresado y puro, de un verdadero impulso del espíritu basado en los ademanes de la vida misma" (129).

Sin embargo, "con esa manía de rebajarlo todo que es hoy nuestro patrimonio común, tan pronto como dije 'crueldad' el mundo entero entendió 'sangre” (90), se lamentaba Artaud. Y en efecto, pese a sus abundantes advertencias al respecto, es una interpretación banalizada y justamente cotidiana de la palabra "crueldad", entendida en su significado más habitual -y totalmente opuesto por tanto a las pretensiones de Artaud-, la que ha permitido vincularla con una supuesta influencia artaudiana en el teatro de Gambaro (así lo hacen Holzapfel, Laughlin o Zee, entre otros críticos), influencia que en este caso concreto es posible $-\mathrm{y}$ necesario - negar con plena rotundidad. Porque no hay otra crueldad en la textualidad gambariana que ésa cotidiana y absolutamente negativa, ligada al ejercicio y abuso del poder, hecho social y ético y no determinismo ontológico de potencia vital; crueldad "como vicio" plasmada en el horror, el miedo y la violencia que signan las relaciones humanas y ante la que el hombre tendría que tomar conciencia, asumir su responsabilidad y elevar su voz, su acción, para decir no. Basta leer cualquier obra de Griselda Gambaro para comprobarlo; y veamos de hecho cómo usa la autora el término "crueldad" al referirse a su teatro:

Yo no te diría que el hombre es cruel. Yo digo que el hombre, y eso lo sigo creyendo, es un ser muy pasivo a quien le cuesta asumir su responsabilidad con respecto a los otros y con respecto a sí mismo. Y creo que esto está indicado en mis primeras piezas. Siempre me preocupó eso de encerrarse y no asumir la responsabilidad que tenemos, porque esa actitud nos lleva a la destrucción 
y a la muerte. Mira la política mundial, es un camino hacia la muerte, porque no es un camino hacia el crecimiento, hacia la madurez, hacia las posibilidades de la vida, no. Es un camino hacia el armamentismo, hacia la guerra, hacia el hambre, hacia el juego del poder, hacia los intereses más egoístas. Y nosotros seguimos protegiendo nuestro pequeño lugarcito como si eso no nos fuera a tocar nunca. Lo que pasa es que el hombre se dice: Yo voy a vivir 70 u 80 años y después el diluvio, pero a veces nos puede tocar y nos toca, ¿no? Es decir, que no es que yo plantee eso como fatalidad o como si fuera inexorable. Es como quien golpea una puerta para que la gente se dé cuenta donde está y despierte (Giella, 28).

Siempre hay una delegación de crueldades. Eso también es lo terrible de nuestra historia, no te digo de nuestra condición. El que tiene más poder delega. La esperanza es que alguna vez esa cadena ininterrumpida de delegación de crueldades se quiebre y haya uno que diga que no. Porque por lo general pasa así como axioma, simplemente uno escribe las obras con los datos de la experiencia, con lo que uno ve, con lo que uno lee en los diarios. Y lo terrible es que el poder o la crueldad no son abstracciones, están encarnados, es decir hay seres humanos que son crueles, que tienen autoridad desmedida. Hay seres humanos que ejercen poder dictatorial, pero ¿por qué lo ejercen? Porque hay toda una cadena, hay toda una delegación y nadie asume una responsabilidad de decir "yo no voy a hacer las cosas de esta manera". (Giella, 30)

Para terminar con esta revisión deslindada del alcance de las vinculaciones que pueden establecerse entre el teatro de la crueldad artaudiano y la dramaturgia de Griselda Gambaro, resulta conveniente volver por último a otro punto que ya dejábamos indicado en nota al pie muy al comienzo de este trabajo: la cuestión del autor-director propugnado por Artaud como artífice privilegiado de un teatro verdadero que ha de nacer de la escena y no de un texto previo. Recordemos algunas de sus palabras al respecto: "un teatro que subordine al texto la puesta en escena y la realización - es decir, todo lo que hay de específicamente teatral- es un teatro de idiotas, de locos, de invertidos, de gramáticos, de tenderos, de antipoetas, de positivistas, es decir occidental" (46); "la puesta en escena es instrumento de magia y hechicería; no reflejo de un texto escrito. [...] el autor que sólo emplea palabras escritas nada tiene que hacer en el teatro" (84); "las posibilidades de realización del teatro pertenecen por entero al dominio de la puesta en escena, considerada como lenguaje en el espacio y en movimiento" (51), "y en el manejo de ese lenguaje se disolverá la antigua dualidad de autor y director, reemplazados por una suerte de creador único, al que incumbirá la doble responsabilidad del espectáculo y la acción" (106); "a mi entender, sólo tiene derecho a llamarse autor, es decir creador, quien tiene a su cargo el manejo directo de la escena" (133).

Toda esta concepción artaudiana viene a añadirse en su conjunto a las limitaciones de la posición de Gambaro en tanto receptora de Artaud. Si bien las obras dramáticas de la autora argentina están desde luego pensadas y escritas 
para la escena y tienen en cuenta la especificidad de esa condición de "ser para la representación", es en el texto y en el escritorio donde se construye la propuesta de Gambaro, que ha permanecido siempre deliberadamente al margen de una labores de dirección que considera ajenas a su oficio:

Yo llegué al teatro por la lectura, lo cual desmiente un poco eso de que uno tiene que estar en contacto con los actores, en contacto con el escenario para escribir teatro. Creo que es válido para algunos autores o para muchos, pero en mi caso debo confesarte que fue a través de la lectura y diría que más que una dramaturga yo me considero una escritora, es decir, lo que me importa a mí es escribir (“Diálogo", 19).

$Y$ aunque Gambaro acepta que "una cosa es lo que plantea el texto como texto literario y otra cosa es el montaje sobre el escenario y así tiene que ser", también defiende que "debería conservarse el pensamiento original: ese texto tiene que llegar al escenario sin traicionar al autor, respetándolo" (cit. Tarantuviez, 199-200); es decir, todo lo contrario que propugna Artaud con su rechazo del texto previo y preeminente a la puesta en escena. E incluso es más, si tomásemos rigurosa y literalmente las afirmaciones de Artaud, Gambaro carecería a su juicio del derecho de llamarse propiamente autora, creadora, pues nunca ha tomado "a su cargo el manejo directo de la escena" (Artaud, 133), y por tanto en ningún caso podría asimilar la totalidad orgánica del entramado de ideas del teatro de la crueldad.

No obstante, lo que la dramaturgia de Griselda Gambaro sí va a contribuir a abrir de manera fundamental con su consagración va a ser el camino para toda una serie de creadores que protagonizarán un amplio movimiento rupturista de superación ya generalizada de ese imperio del realismo que dominaba el panorama argentino anterior, cultivando múltiples y diversas formas de abordar las prácticas escénicas, que permitirán en algunos casos una mayor afinidad con la radicalidad de la especificidad teatral planteada por Artaud. Así, por ejemplo, frente a la dramaturgia de autor que dominó las décadas anteriores, el teatro argentino de los años ochenta se caracterizará por la reivindicación de una dramaturgia plenamente independiente de lo literario, desligada de un texto previo o incluso desprovista de todo componente verbal en el escenario, y elaborada a partir de la improvisación y la creación colectivas, apoyadas según el caso en un guión que operaba más como una base utilitaria para la escenificación que como un elemento de índole artística en sí mismo. Representado, entre otros muchos, por grupos como Las Gambas al Ajillo, el Clú del Claun o Los Macocos, y ligado a espacios como el Parakultural, Cemento, o el Centro Cultural Ricardo Rojas, este teatro "under" de los ochenta dará paso en la década siguiente a una nueva generación de dramaturgos que, combinando la labor autorial con la dirección escénica, recuperan el texto en sus puestas para transformarlo en un foco central de experimentación, problematización y reflexión teatral. Es el caso de 
autores, hoy ya consagrados, como Alejandro Tantanian, Daniel Veronese, Rafael Spregelburd, Luis Cano, Javier Daulte o Federico León, que a través de sus obras reubican, reinterpretan y refuncionalizan en muy diversas direcciones las relaciones de dependencia e independencia entre literatura y teatro, entre palabra y escena.

\section{BIBLIOGRAFÍA}

Artaud, Antonin. El teatro y su doble. Trad. Enrique Alonso y Francisco Abelenda. Barcelona: Edhasa, 2001.

BlüHer, Karl Alfred. "La recepción de Artaud en el teatro latinoamericano”. Semiótica y teatro latinoamericano. Ed. Fernando de Toro. Buenos Aires: Galerna, 1990. 113-131.

Carballido, Emilio. "Griselda Gambaro o Modos de Hacernos Pensar en la Manzana”. Revista Iberoamericana 36.73 (octubre-diciembre 1970): 629-634.

Contreras, Marta. Griselda Gambaro. Teatro de la descomposición. Concepción (Chile): Ediciones Universidad de Concepción, 1994.

Cypess, Sandra M. "Physical Imagery in the Works of Griselda Gambaro". Modern Drama 8.4 (diciembre 1975): 357-364.

De Marinis, Marco. "Artaud y el segundo Teatro de la Crueldad”. Tradición, modernidad y posmodernidad. Teatro iberoamericano y argentino. Ed. Osvaldo Pellettieri. Buenos Aires: Galerna, 1999. 49-62.

De Toro, Fernando. "La articulación del discurso en los textos de Griselda Gambaro". Espacio de Crítica e Investigación Teatral 6.7 (1990): 35-38.

"Diálogo de apertura: Griselda Gambaro y Osvaldo Pellettieri”. El teatro y su crítica, Ed. Osvaldo Pellettieri. Buenos Aires: Galerna, 1998. 19-27.

Dubatti, Jorge. "Antonin Artaud, el actor hierofánico y el primer Teatro de la Crueldad". Revista Colombiana de las Artes Escénicas 2.1 (enero-junio 2008): 70-83.

Eidelberg, Nora. "La ritualización de la violencia en cuatro obras teatrales hispanoamericanas”. Latin American Theatre Review 13/1 (1979): 29-37.

Gambaro, Griselda. “Teatro de vanguardia en la Argentina de hoy". Revista de la Universidad del Litoral 81 (julio-diciembre 1970): 301-332.

—, "Por qué y para quién hacer teatro". Talía 39/40 (1972): 4-5.

- Teatro 2. Buenos Aires: Ediciones de la Flor, 1987.

—, Teatro 3. Buenos Aires: Ediciones de la Flor, 1989.

—, Teatro 4. Buenos Aires: Ediciones de la Flor, 1990.

Giella, Miguel Ángel et al. "Entrevista. Griselda Gambaro: La difícil perfección”. Griselda Gambaro. Teatro: Nada que ver. Sucede lo que pasa. Ottawa: Girol Books, 1983. 21-37.

Holzapfel, Tamara. "Griselda Gambaro's Theatre of the Absurd”. Latin American Theatre Review 4/1 (1970): 5-11.

Laughlin, Karen L. "The Language of Cruelty: Dialogue Strategies and the Spectator in Gambaro's El desatino and Pinter's The Birthday Party". Latin American Theatre Review 20/1 (1986): 11-20. 
Ostergaard, Ane-Grethe. "La semiótica del diálogo en "El campo" de Griselda Gambaro". Semiótica y teatro latinoamericano. Ed. Fernando de Toro. Buenos Aires: Galerna, 1990. 267-276.

Pellettieri, Osvaldo, ed. Historia del Teatro Argentino en Buenos Aires. La segunda modernidad (1949-1976). Buenos Aires: Galerna, 2003.

Picón Garfield, Evelyn. "Una dulce bondad que atempera las crueldades: El campo de Griselda Gambaro". Latin American Theatre Review 13/2 (1980): 95-101.

Postma, Rosaela. "Space and Spectator in the Theatre of Griselda Gambaro: Información para extranjeros". Latin American Theatre Review 14/1 (1980):35-45.

SÁnchez, José A., ed. La escena moderna. Manifiestos y textos sobre teatro de la época de las vanguardias. Madrid: Akal, 1999.

Tarantuviez, Susana. La escena del poder. El teatro de Griselda Gambaro. Buenos Aires: Corregidor, 2007.

ZeE, Linda S. "El campo, Los siameses, El Señor Galindez: A Theatrical Manual of Torture”. Romance Languages Annual 2 (1990): 604-608.

Nombre del autor: Ana Sánchez Acevedo

Dirección-e: $\quad$ anacevedo@us.es

Dirección postal: Dpto. de Filologías Integradas, Facultad de Filología, C/ Palos de la Frontera, s/n, 41004, Sevilla

Fecha de recepción: 30/10/2011

Fechade aceptación: 11/12/2012 